\title{
An Experiment Design for Determining the Volume of Traditional Eucalyptus Oil with Variations in Fluid Flow Speed
}

\author{
Nur Hamida Siregar ${ }^{1}$, Moh. Toifur ${ }^{2}$, and Yudhiakto Pramudya ${ }^{3}$ \\ ${ }^{1}$ Physics Education, Darussalam University Ambon, ${ }^{2,3}$ Physics Education, Ahmad Dahlan University \\ ${ }^{1} \mathrm{Jl}$. Waehakila Puncak Wara, Ambon-97128, ${ }^{2,3} \mathrm{Jl}$. Pramuka No.42, Pandeyan, Umbulharjo, \\ Yogyakarta-55161 \\ Nurhamidasiregar12@gmail.com
}

\begin{abstract}
This study aimed to determine the volume of traditional eucalyptus oil from distillation with variations in fluid flow velocity. The method of distillation was distillation with water (water distillation). The material was eucalyptus leaves. To determine the volume of eucalyptus oil produced by distillation, the distillation device was set at the height of the condenser to the source of flow fluid, which was at an altitude of $15 \mathrm{~cm}, 25 \mathrm{~cm}, 35 \mathrm{~cm}, 45 \mathrm{~cm}$, and $55 \mathrm{~cm}$. Variation in the height of the condenser would affect the fluid flow rate. The faster the fluid flow rate, the greater the convection coefficient so that it increased the heat transfer rate. This results in greater volume (capacity) of oil produced. From these experimental results, most volumes of eucalyptus oil obtained from the distillation was obtained at $55 \mathrm{~cm}$ of the height of condenser with $3.6 \mathrm{~mL}$ of oil volume.
\end{abstract}

Keywords: Eucalyptus oil, Water distillation, Volume, Altitude, Condenser.

\section{Introduction}

Traditional medicine has increasingly gained attention in recent years, both medical and industrial circles. It was because of the potential as alternative medicine and a promising prospect for the household product industry, especially the pharmaceutical industry. The main benefit of this oil is to accelerate blood circulation by widening the pores of the skin so that the body becomes warmer and will not interfere with skin respiration due to the nature of volatile eucalyptus oil. Because of its wide using, the quality and method of producing eucalyptus oil sold in the market need attention.

In order to fulfill these demands, research is needed. To find out the quality of eucalyptus oil, testing the level of purity was conducted. Testing the level of purity can be conducted in 2 ways, namely: visual tests and laboratory test methods.

There are several factors that influence the production of eucalyptus oil: leaf filling, eucalyptus oil tree varieties, leaf storage, leaf age and distillation technique [1]. To obtain the production (volume) of maximum eucalyptus oil was conducted in one way, by varying the fluid flow rate in the distillation technique.

\section{Theory}

\section{A. Eucalyptus Oil}

Eucalyptus oil plant (Melaleuca Leucadendra) is one of the plants producing essential oils. These plant leaves contain essential oils about $0.5-1.5 \%$ depending on the effectiveness of distillation and the oil content contained in distilled material [2]. Eucalyptus leaves can be seen in figure 1 .

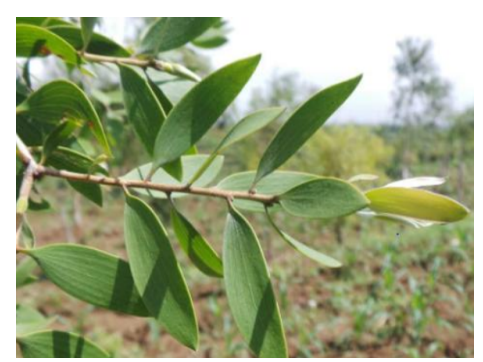

Figure 1. Eucalyptus leaves

Essential oils produced from the leaves are useful as raw material for rubbing oil which has many functions, such as analgesics or pain relievers, disinfectants or germ killers, expectorants or sputum and anti-spasmodic decay or abdominal pain relief [3]. 


\section{B. Water Distillation}

In this distillation method, the material to be distilled is directly related to boiling water. The material to be distilled may float on water or be submerged entirely, depending on the specific gravity and quantity of the material to be processed. Water can be boiled directly with fire. This water distillation is like a directly boiled plant material [4].

\section{Condensation}

Condensation is a process of releasing heat from a system that causes steam (vapor) to turn into liquid (liquid). The condensed liquid from the vapor is called condensate. The tool used to condense vapor into a liquid is called a condenser. The working principle of the condenser is that the substance is heated, then the hot steam will rise and then run cold water through the hose so that the steam does not escape into the air but returns to condense and fall down again [5].

\section{Basic Principles of Flow in Pipes}

Fluid or liquid is a form of a substance that does not have a fixed form, but can flow and take shape according to the container it occupies.

1. Flow Debit Equation

Mathematically the flow debit can be written:

$$
Q=A \cdot v
$$

With $Q$ is the flow rate $\left(\mathrm{m}^{3} / \mathrm{s}\right), A$ is the crosssectional area of the pipe $\left(\mathrm{m}^{2}\right)$ and $v$ is the average velocity in the channel $(\mathrm{m} / \mathrm{s})$.

\section{Continuity Equation}

The equation which states the relationship between cross-sectional area and fluid velocity is called a continuity equation, and is mathematically written as follows:

$$
A_{1} v_{1}=A_{2} v_{2}
$$

with $A_{1}$ is a cross-sectional area of $1\left(\mathrm{~m}^{2}\right)$, is the rate of fluid flow when through cross section 1 $(\mathrm{m} / \mathrm{s}), A_{2}$ is the cross-sectional area of $2\left(\mathrm{~m}^{2}\right)$ and $v_{2}$ is the rate of fluid flow when passing through cross section $2(\mathrm{~m} / \mathrm{s})$. Continuity equations can also be written:

$$
Q_{1}=Q_{2}
$$

\section{Bernoulli Equation}

Bernoulli provides a mathematical formulation that states the relationship between the pressure in a fluid, fluid flow and the difference in cross-sectional height is constant (constant). This mathematical formulation is called the Bernoulli equation which is written as follows:

$$
P+\frac{1}{2} \rho v^{2}+\rho g h=t e t a p
$$

Equation (4) can also be written as follows:

$$
P_{1}+\frac{1}{2} \rho v_{1}^{2}+\rho g h_{1}=P_{2}+\frac{1}{2} \rho v_{2}^{2}+\rho g h_{2}
$$

with $P_{1}$ and $P_{2}$ are the fluid pressure in cross sections 1 and $2\left(\mathrm{~N} / \mathrm{m}^{2}\right), \rho$ is the density of fluid $\left(\mathrm{kg} / \mathrm{m}^{3}\right), v_{1}$ and $v_{2}$ are the velocity of fluid flow in sections 1 and $2(\mathrm{~m} / \mathrm{s}), g$ is the gravitational force $\left(\mathrm{m} / \mathrm{s}^{2}\right), h_{1}$ and $h_{2}$ are the height of cross-sections 1 and $2(\mathrm{~m})[6]$.

E. Relationship between Height of Reservoir and Velocity of Fluid Flow

To find fluid flow velocity at a certain height with pipe diameter (D) and condenser diameter (d), use equation (5) with assumptions $P_{1}=P_{2}=0, h_{1}=h$ and $h_{2}=0$, so that equation (5) becomes:

$$
v_{1}^{2}+2 g h=v_{2}^{2}
$$

From equation (2) for a steady flow it is not compressed, it is known that the conservation requirements of mass $Q_{1}=Q_{2}$, with $Q=A \cdot v$. Then obtained equation (7):

$$
v_{1}=\left(\frac{d}{D}\right)^{2} v_{2}
$$

By subsidizing equation (7) to equation (7), to obtain equation (8):

$$
v_{2}=\sqrt{\frac{2 g h}{1-\left(\frac{d}{D}\right)^{4}}}
$$

From equation (8), it can be concluded that the greater the fluid height of the condenser, the greater the fluid flow rate in the condenser. The faster or large fluid flow rate will affect the magnitude of the convection coefficient so that it increases the heat transfer rate. This results in a greater capacity of oil produced or produced [7].

\section{F. Convection Heat Transfer}

Convection heat transfer occurs due to temperature differences. The heat transfer rate or convection heat in the fluid is proportional to the cross-sectional area $A$ of an object that is in contact with the fluid and the temperature difference between the fluid and the object $\Delta T$ stated in equation (9).

$$
\frac{\Delta q}{\Delta t}=i A \Delta T
$$


With $i$ is the convection coefficient. To determine the value of the convection coefficient $(i)$ can be obtained by decreasing equation (9) to obtain equation (10).

$$
i=\frac{m c \frac{\left(T_{2}-T_{1}\right)}{\left(t_{2}-t_{1}\right)}}{A\left(T_{p}-T_{f}\right)}
$$

By $q$ is the convection heat transfer rate (W), $i$ is the convection coefficient $\left(\mathrm{W} / \mathrm{m}^{2} \mathrm{~K}\right), m$ is the mass of the distilled material $(\mathrm{kg}), c$ is the heat of the type of water vapor $(\mathrm{J} / \mathrm{kgK}), T_{1}$ is the initial steam temperature $(\mathrm{K}), T_{2}$ is the steam temperature end $(\mathrm{K}), t_{1}$ is the time of initial steam discharge $(\mathrm{s}), t_{2}$ is the time of final steam discharge (s), $A$ is the heat transfer surface area $\left(\mathrm{m}^{2}\right), T_{p}$ is the surface temperature $(\mathrm{K})$, and $T_{f}$ is the temperature of fluid (K).

\section{Research Methods / Experiments}

A. Tools and materials

1. 1 set distillaionstall

2. Electrothermal

3. Storage container

4. Measuring cup

5. Adhesive as a glass cover

6. Pipe (hose)

7. Thermocouples

8. Ruler

9. Water

10. Stopwatch

11. Separating funnel

12.Digital balance.

B. Research Design

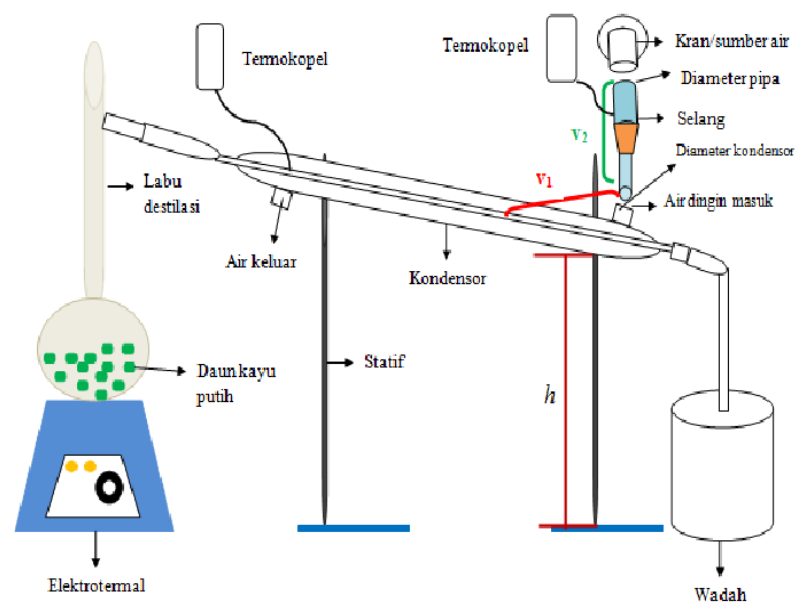

Figure 1. Design experiment
C. Experimental Procedure

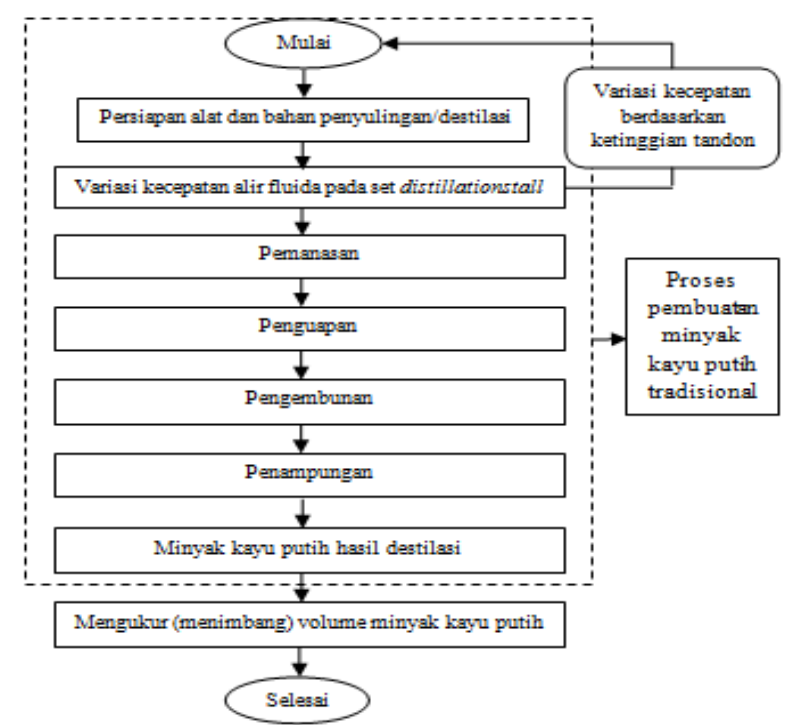

Figure 2. Experimental procedure

\section{Research Results And Discussion}

Based on the results of research carried out for 5 variations of fluid flow velocity based on the height of the condenser in the set distillaionstall, data such as below are obtained:

Table 1. Data Analysis

\begin{tabular}{cccc}
\hline No. & $\begin{array}{c}\text { The height of } \\
\text { the condenser, } \\
h(\mathrm{~m})\end{array}$ & $\begin{array}{c}\text { Flow Rate of } \\
\text { Fluid, } v_{2}(\mathrm{~m} / \mathrm{s})\end{array}$ & $\begin{array}{c}\text { Volume of } \\
\text { Eucalyptus } \\
\text { Oil }(\mathrm{mL})\end{array}$ \\
\hline 1 & 0,15 & 1,79 & 2,0 \\
2 & 0,25 & 2,31 & 2,4 \\
3 & 0,35 & 2,74 & 2,7 \\
4 & 0,45 & 3,10 & 3,1 \\
5 & 0,55 & 3,43 & 3,6 \\
\hline
\end{tabular}

From table 1 a linear curve was obtained as shown in Figure 2 below:

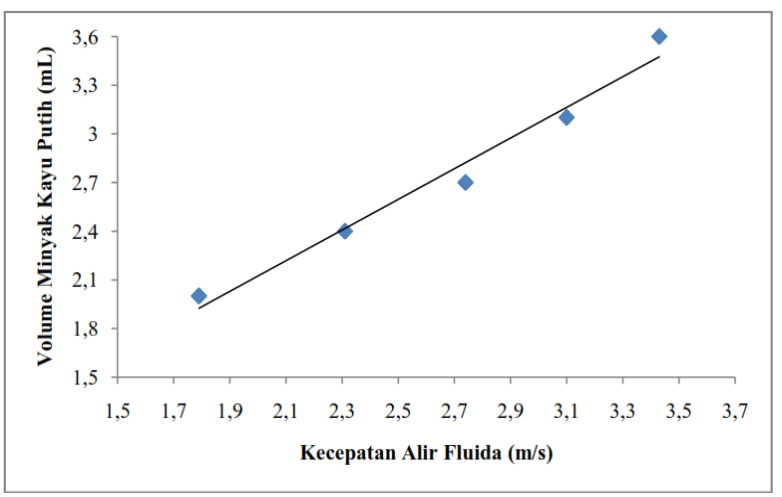

Figure 3. Relationship of fluid flow velocity with volume refined eucalyptus oil

Figure 3 is a graph of the relationship between fluid flow velocity and the volume of refined eucalyptus 
oil. From the linear regression data fitting in the figure, was obtained

$$
y=0,944 x+0,234
$$

where $x$ is the fluid flow velocity $(\mathrm{m} / \mathrm{s})$, and $y$ is the volume of eucalyptus oil ( $\mathrm{mL})$.

Based on the results of the graph in Figure 2 obtained $R^{2}$ a fairly high value of 0.973 close to number 1 which showed the relationship of fluid flow velocity with the volume of eucalyptus oil was really accurate with the accuracy of $97.3 \%$.

From data in table 1 and figure 3 , it can be seen in accordance with equation (8) and the theory which explains that the condenser height affected the velocity of the fluid flow rate. The higher the condenser, the faster the fluid flow rate. The greater the fluid flow rate, the greater the convection coefficient which resulted in greater convection heat transfer rates. Thus, the condensation process also required a shorter time to convert the vapor particles into water particles. Because the time needed in a process was shorter, the volume of oil produced was even greater in the same timeframe for refining each sample of eucalyptus oil.

\section{Conclusion}

From the experiments that have been done, it can be concluded that the variation in the height of the condenser influenced the fluid flow velocity. The faster the fluid flow rate, the greater the heat transfer coefficient so that it increased the heat transfer rate. This resulted in greater volume (capacity) of oil produced. This is evidenced by the highest volume of eucalyptus oil produced by distillation at the height of the $55 \mathrm{~cm}$ condenser with an oil volume of $3.6 \mathrm{~mL}$.

\section{Acknowledgment}

The researcher is grateful to my friend, Kamaluddin who has helped me during the research process, and other friends who cannot be mentioned one by one.

\section{Reference}

[1] P. Armita, Effect of Varieties and Density of Eucalyptus Leaves in Kettles on Eucalyptus Oil Production and Quality. Thesis, Department of Forest Products Faculty of Forestry, Bogor Agricultural Institute, Bogor, 2011.

[2] T.L. Lutony dan Y. Rahmawati, Essential oils, Penebar Swadaya, 1999.

[3] F.L. Astuti dan I.M. Aphari, Extraction of eucalyptus leaves (Melaleuca leucadendra L) using ethanol solvent by maceration extraction method. A Research report, Faculty of Engineering Chemical, Engineering Department Sultan Ageng Tirtayasa University, Banten, 2013.

[4] H. Sastrohamidjojo, Chemistry of essential oils, Gadjah Mada University Press, 2004.

[5] F. Ardi, Phenomenon of condensation on textile ducting made from polyester. Thesis, Faculty of Engineering,
Department of Mechanical Engineering, University of Indonesia, Depok, 2012.

[6] D.C. Giancoli, Principles and application of the seventh edition of volume I, PT Gelora Aksara Praatama, 2014.

[7] S. Haryadi, Effect of cooling water flow direction on the condenser on the condensation results of the waste plastic pyrolysis process. Thesis, Faculty of Engineering, Department of Mechanical Engineering, Universitas Negeri Malang, Malang, 2015. 